\title{
Strategy Research of Piano Impromptu Accompaniment Teaching in College Music Education
}

\author{
Xueying Liu \\ Cai Jikun Conservatory of Music, Minjiang University, Fuzhou, Fujian Province, China
}

Keywords: college music education; piano impromptu accompaniment; teaching strategies

\begin{abstract}
College music education is an integral part of quality education for college students. Piano impromptu accompaniment is the main content of instrumental music performance. To explore college piano impromptu accompaniment teaching and find ways and means to improve the level of piano teaching is conducive to improving the level of college students playing and improving the overall quality of college students.
\end{abstract}

\section{Introduction}

As an impromptu piano music accompaniment, it is a required course for advanced music education majors. The importance and practicality of the curriculum has been recognized by teachers and students. Piano improvisational accompaniment has become an essential basic skill for music education students and an important component of teaching skills. For many years, many teachers of piano and composition majors have worked diligently in the teaching field of improvisational accompaniment [1]. They basically created a more systematic teaching model, and published a large number of high-level series of textbooks. However, with the deepening of China's basic education reform, the renewal of education concepts, the implementation of new music curriculum standards, and the industrialization of education and the establishment of a new higher education structure, we should re-evaluate the piano at a higher level. The impromptu accompaniment course cultivates students' overall musical quality and their role in the comprehensive and cohesive music professional courses [1]. Through improvisational accompaniment and improvisational teaching, students cultivate creative music thinking and rich imagination, and establish self-confidence and cooperation spirit. Maximize the potential quality and ability of students.

In recent years, piano music impromptu accompaniment courses have been set up in music education majors in various universities in China. Research on various aspects of teaching has also seen initial success. However, in many aspects of information feedback, the teaching of impromptu accompaniment is still the weakest link in music teaching in normal universities [1]. In view of the actual state of higher music education in China and the future development trend, in combination with the new concept of basic music education curriculum standards, in the face of abnormally active contemporary college students, our improvisational accompaniment reform and construction should be carried out in order to study more deeply Knowledge structure, teaching organization, teaching methods and methods, evaluation and assessment standards.

\section{The Definition and Characteristics of Impromptu Accompaniment}

\subsection{The definition of impromptu accompaniment}

Instead of writing a formal accompaniment spectrum, the piano can quickly and effectively pop up accompaniment that is in tune with the mood of the song, and play a complementary role to the song. It is a combination of theoretical composition and piano playing skills. Impromptu accompaniment is an essential teaching skill for college music teachers. Therefore, it has become a major course for music education majors in normal universities [2]. In general, the piano teaching in normal colleges focuses more on the training and teaching of skills. There are progressive tracks and teaching materials. It is undoubtedly necessary for students to systematically master the ability of piano 
performance. However, piano teaching cannot substitute the teaching of piano improvised accompaniment.

\subsection{The characteristics of impromptu accompaniment}

Impromptu accompaniments can accompany vocal, instrumental, dance, or poetry readings [2]. In addition, some talk shows, talk shows, and many singing competitions of TV stations also use live improvisations, such as "Art Life" and "Super Girl", etc. Therefore, impromptu accompaniment has a wide range of practicalities.

\section{Problems in Piano Impromptu Accompaniment Teaching in Colleges and Universities}

\subsection{Problems from student}

Supervised learning learns a function from a given set of training data. When new data arrives the result can be predicted based on this function. The training set requirements for supervised learning include input and output as well as features and goals. The goal of the training set is marked by people [3]. Common supervised learning algorithms include regression analysis and statistical classification. The difference between supervised learning and unsupervised learning is whether the training set target is marked. They all have training sets and both input and output unsupervised learning compared to supervised learning. The training set has no artificially labeled results. Common unsupervised learning algorithms have clustering. Semi-supervised learning is between supervised learning and unsupervised learning. Enhanced learning learns how to make actions through observation [1]. Every action will have an impact on the environment. Learning objects make judgments based on the feedback of the observed surrounding environment.

\subsection{Problems from teacher}

A large number of students in Chinese universities have relatively short enrollment periods, and students have relatively weak basic music knowledge when they enter school. Therefore, these students have difficulty mastering accompaniment skills in a short period of time. Students with weak music foundations generally have the following phenomena: Because students do not have sufficient skills in piano performance because they do not have long-term and systematic training, it is difficult to determine the accompaniment patterns in the learning process [2]. There is a certain degree of difficulty; during the process of accompaniment, some basic sound patterns may not be discernible, and the purpose of piano teaching cannot be achieved. Due to the general lack of theoretical basis, the grasp of tonality in the course of accompaniment will be inaccurate. In addition, most of the students' thinking is relatively fixed and they only follow the specific melody to accompany them. There is no way they can't adapt the piano accompaniment to the actual situation at that time [3]. The students with a better piano accompaniment are generally more steadfast in their playing skills than the students whose music basic knowledge is weaker. However, in actual practical applications, there is no way to skillfully combine their skills with the situation at the time and transform them into improvisations. During the process of accompaniment, there are still no skilled playing techniques.

\section{Ways to Improve Piano Impromptu Accompaniment Teaching in College Teachers' Music Education}

\subsection{Strengthen the teaching staff}

Colleges and universities should appropriately introduce professional teachers so that schools can have a high-quality teaching staff and lay a solid foundation for the teaching of music majors. In addition, the teaching level of teachers has a crucial influence on the enthusiasm and effectiveness of student learning. A professional piano accompaniment teacher must first have a solid playing basic skill and professional music literacy, and secondly, he must have the theoretical literacy that is necessary in piano accompaniment teaching. China's current education requires teachers to implement the "people-oriented" teaching philosophy [3]. Therefore, in the piano accompaniment 
teaching process, teachers should focus on how to develop relevant learning plans for students instead of formulating teaching tasks that suit their abilities. In the teaching process of piano accompaniment, teachers should focus on cultivating students' creativity and imagination. They should not use specific scores to limit students' thinking. In addition, colleges that offer music majors can co-publish related materials and explore a curriculum system combining practice and theory to improve the professional level of piano accompaniment teachers. In addition, the school can open lectures on improving the teaching level of piano teachers so that teachers can give themselves a position through these lectures.

\subsection{Strengthen piano accompaniment teaching practice}

In most college education, teachers often only focus on granting students theoretical knowledge in books, and they neglect to provide students with practical opportunities. However, students' piano accompaniment skills are generally trained in practice. In the absence of such practical teaching, students tend to have inconsistent songs and inconsistencies between the genre and the style of the piano [4]. The music played in this way tends to greatly reduce the viewing effect. Therefore, schools should create more practical opportunities for music students, such as large-scale performances. This large-scale and small-scale deduction exercise just gives students the opportunity to improve themselves and exercise themselves. Such activities can not only improve their ability to resist pressure, but also exercise their self-expression capabilities and improve the adaptability of the environment. On the other hand, through such exercise, not only can they improve their mental capacity, but also help their typhoon, music coordination, and performance appreciation.

\subsection{Inspire students' interest in the course and their enthusiasm for learning}

Instructors should stimulate students' interest in piano improvised accompaniment lessons from all angles, so that students' learning is very active from the very beginning. First of all, from the aspect of interest, you can choose popular songs that young college students are keener on as part of the teaching track [4]. These popular songs should be more popular in recent years, with strong melody and obvious harmony frame. Second, from the perspective of practicality, guide students to establish a correct concept, to make it recognize the future of the music education profession practitioners and development direction. The purpose of teaching is to cultivate qualified Chinese and university music teachers. Thanks to the two-year piano required course, students have been given a certain improvement in their piano skills. Some students will not enter the school at all and will not be able to reach Carney's 849, 299 or higher levels after two years. Although not as good as a piano student, this study can lay a solid foundation for piano accompaniment. In the future, students may spend most of their time sitting in the classroom playing accompaniment for students, and only playing solo on the stage for a very small amount of time [4]. Therefore, strengthening piano impromptu accompaniment ability is one of the most important tasks of college music education students. Most of the training programs for music education majors in normal colleges place piano improvisational accompaniment classes in their junior year. There will be an education practice in the first half of the senior year.

\subsection{Change the concept of piano accompaniment education}

In addition to improving the students' ability to accompany their piano music, we should also establish a correct educational philosophy. The key to education in piano accompaniment really lies in the transformation of educational concepts. We should find the position of piano accompaniment in music education. Schools should organize scholars with long years of working experience in music education to write piano accompaniment materials, in order to promote the improvement and formulation of the Ministry of Education, and establish the importance of the status of piano accompanists in the minds of teachers and students [5]. Teachers should be people-oriented in piano accompaniment teaching. Students should not be able to generalize in accordance with their aptitude. They should not be generalized, but should focus on the characteristics of students and educate them. For students with a good sense of innate music, but lack of skills, take a step-by-step approach to education, and gradually improve their personal skills; For piano accompaniment skills slightly better, but lack of sense of music students should follow their good feelings to enhance his music In addition to interest, the teacher should also understand the student's personal interests, excavate their 
advantages and disadvantages based on their interests, and give them timely corrections [5]. And music education can not only stay in the skills of education, but also should strengthen students' appreciation of music, but also should enhance the students' music literacy, start students' creativity and creativity, stimulate students' love of music. To this end, the school should provide students with rich and wonderful music appreciation, entertaining, and actively guide students to the path of attractive music. Only the implementation of the various training paths above will enhance the students' ability to play piano accompaniment.

\subsection{Course setting and improvement of teaching methods}

Judging from the current enrollment situation of the music education majors of our country and the current college entrance examination system, most undergraduates in the music education majors fail to get undergraduate courses because of their cultural grades, and they temporarily learned their music for a few months (mostly vocal music The main item) took a professional examination [6]. Therefore, most music education students do not have basic skills in piano performance when they enter school. Some of them even played several pieces of music. They were only prepared for examinations. 24 scaled scales only played one or two, and the overall academic quality of musicology was also relatively poor. Therefore, it is necessary to go through the formal piano study of the two-year system and to strengthen music theory, practice and ear training, and systematically study the basics of composition theory such as harmony, music composition analysis, song writing, etc., and master the basic knowledge and skills of systematic musicology. After composing the basic theory, the piano improvisational accompaniment course can only be started in the third year. This has been established in most university teaching programs.

The traditional piano impromptu accompaniment teaching method is that the teacher conducts large class teaching in a large classroom equipped with piano, and the teacher mainly uses the piano to play the teacher. What students can do is to listen carefully and have no chance to practice in class. The author suggests that in the teaching of piano impromptu accompaniment classes for music education majors in normal universities, small class collective lessons should be adopted [6]. Small class classes should be taught in classrooms with 15-20 pianos or electric pianos. During class hours/weeks, the class teacher system will talk about the theoretical knowledge of improvised accompaniment, and students will be able to practice in class immediately.

\subsection{Experimental teaching methods and improvements}

Teachers should focus on cultivating students' enthusiasm for experimentation in order to test their piano accompaniment level and their ability to operate and adapt in practice. Encourage students to use more pianos for improvisation accompaniment and add social activities. Applying the learned knowledge to practice will further improve the student's accompaniment level [7]. The author proposes to take the "back-to-song demonstration" (that is, one person playing accompaniment and singing one or more people) inside the class once a month as part of the score of the course exam so that every student has the opportunity to show their accompaniment in class. In the course of examination, teachers can also invite other teachers or students from other classes as spectators to increase the sense of presence and seriousness of the entire process and exercise their psychological qualities [7]. Qualified teachers' colleges and universities may also require rehearsal education. Important students must design songs for piano excuses during the course of lesson preparation in the education practice, and rehearse them during the lecture.

Other more targeted methods such as playing accompaniment for ballad competitions, choir performances, etc. inside and outside the school; students in the vocal music examination can also play accompaniment for each other; students with a poor piano foundation can pick up some lower grades. The simple vocal accompaniment comes as a practical exercise [7]. However, these activities require fewer students and have certain competition. Not every classmate has the opportunity to participate. Therefore, it can be defined as the content of the student social practice course. Students who participate in this course can get the corresponding credits through assessment. These way students have both stress and motivation. More importantly, in the student's practical activities, teachers should actively guide and follow up, so that students can timely feedback information. 
Through the cooperation of the two parties, teachers can find problems in teaching more quickly, so that they can explore and improve in their future work. Students can also improve their piano accompaniment ability more quickly.

\section{Summary}

In general, piano impromptu accompaniment is a theoretically strong technical course. Only by integrating the comprehensive theoretical knowledge of musicology, especially the theory of composing music, can we successfully perform high-quality "secondary creation". However, it is a very practical course, although the improvisational accompanist is not the audience singer in front of the stage, but it is also the front desk behind the scenes. If an accompaniment is wrong, it will affect the artistic effect of the singing, and it will cause the singer to "run away" and make the concert a mess. Therefore, teachers in the teaching process should create more opportunities for students to practice. Students should also take full enthusiasm and take the initiative to participate in the exercise to strengthen the psychological quality. In order to steadily improve their improvisation accompaniment and on-site resilience, they become a music teacher with strong piano teaching accompaniment ability.

\section{Acknowledgement}

Educational Research Projects for Young Teachers supported by Fujian Provincial Education Department (Project No.: JAS150484).

\section{References}

[1] Y.T. Meng, Exploration of Piano Foundation Course of Music Education Major in Normal Colleges, Popular Literature, 2012, vol.24, pp.48-50.

[2] Z.M. Hou, on piano accompaniment in vocal music teaching, research on children's education development, 2012, vol.4, pp. 22-24.

[3] H.T. Chen, Problems and countermeasures in the teaching of impromptu piano accompaniment for high-efficiency music education, music time and space, 2015, vol.1, pp.98-100.

[4] J.J. Du, Reflections on piano improvised accompaniment, Charm China, vol.5, pp.66-69.

[5] J.Zh. Zhang, A Preliminary Exploration of the Teaching Practice of Junior Piano Accompaniment, Northeast Normal University, 2007, vol.3, pp.10-13.

[6] Y.W. Dong, Comprehensive Application of Related Music Theory Knowledge in Piano Accompaniment, Chinese Music Education. 2006, vol.6, pp.24-26.

[7] Y.Sh. Zhang, on piano teaching accompaniment teaching reform, education and occupation, 2009, vol.33, pp.3-7. 